Avaliable online at https://www.syekhnurjati.ac.id/jurnal/index.php/tamaddun/index Published by Departement of History and Islamic Culture, Faculty of Ushuluddin Adab and Dakwah IAIN Syekh Nurjati Cirebon, Indonesia

\title{
Peranan K.H. Anwar dalam Perkembangan Pesantren Nurul Islam Seri Bandung 1932-1959
}

Syarifuddin

FKIP/Pendidikan Sejarah/Dosen

Universitas Sriwijaya

\section{Supriyanto}

FKIP/Pendidikan Sejarah/Dosen

Universitas Sriwijaya

Ajimiliansyah

FKIP/Pendidikan Sejarah/Mahasiswa

Universitas Sriwijaya

\section{Tedi Rizki}

FKIP/Pendidikan Sejarah/Mahasiswa

Universitas Sriwijaya

\section{Muhammad Fikri}

FKIP/Pendidikan Sejarah/Mahasiswa

Universitas Sriwijaya syarifuddin@fkip.unsri.ac.id

supriyanto@fikipsej@gmail.com

ajimiliansyah@gmail.com

tedyriski99@gmail.com

muhammadfikri@gmail.com

Abstract: This paper discusses the role of K.H. Anwar in the development of the Nurul Islam Seri Bandung (1932). K.H. Anwar's discussion regarding his process in building the Nurul Islam Pesantren Seri Bandung, Ogan Ilir, South Sumatra which originated from K.H. Anwar's journey to study in various places in Ogan Ilir, Jambi to Mecca and Medina. Furthermore, from the beginning he preached in the village of Seri Bandung and held recitation or cawisan, until he planned to establish a boarding school which was realized in 1932 through a long process because licensing was very strict at that time by the Dutch colonial government. K.H. Anwar is a scholar who plays a role in Islamic education in Ogan Ilir district, he has works which later became a reference for use in the Nurul Islam Seri Bandung Islamic boarding school. Pesantren Nurul Islam is one of the oldest Islamic boarding schools in South Sumatra which is currently 92 years old. In this paper, K.H. Anwar focuses on building the Islamic Nuru pesantren such as the pesantren curriculum, writing Islamic boarding school books, the rules of the pesantren that he designed and is still being implemented. This paper uses the historical method with the object of research in the 
Syarifuddin, Supriyanti, Ajimiliansyah, Tedi Rizki, Muhammad Fikri

development of the Nurul Islam Seri Bandung (1932). The purpose of this research is specifically to examine the role of K.H. Anwar in the development of the Nurul Islam Islamic Boarding School Series Bandung 1932-1959. The result of this research is the history of K.H. Anwar's role in the development of the Nurul Islam Islamic Boarding School Series Bandung 1932-1959.

Keywords: Islamic figures, Islamic boarding schools, Islamic history, Ogan Ilir, South Sumatra.

Abstrak: Tulisan ini membahas tentang peran K.H. Anwar dalam perkembangan Pondok Pesantren Nurul Islam Seri Bandung (1932). Diskusi K.H. Anwar tentang prosesnya membangun Pesantren Nurul Islam Seri Bandung, Ogan Ilir, Sumatera Selatan yang berawal dari Perjalanan K.H. Anwar menuntut ilmu di berbagai tempat di Ogan Ilir, Jambi hingga Mekkah dan Madinah. Selanjutnya dari awal beliau berdakwah di desa Seri Bandung dan mengadakan pengajian atau cawisan, hingga beliau berencana untuk mendirikan sebuah pesantren yang direalisasikan pada tahun 1932 melalui proses yang panjang karena perizinan yang sangat ketat pada waktu itu oleh pemerintah kolonial Belanda. K.H. Anwar adalah seorang ulama yang berperan dalam pendidikan Islam di kabupaten Ogan Ilir, beliau memiliki karya-karya yang kemudian menjadi referensi untuk digunakan di Pesantren Nurul Islam Seri Bandung. Pesantren Nurul Islam merupakan salah satu pondok pesantren tertua di Sumatera Selatan yang saat ini berusia 92 tahun. Dalam makalah ini, K.H. Anwar fokus membangun pesantren Nuru Islam seperti kurikulum pesantren, penulisan buku-buku pesantren, aturan pesantren yang ia rancang dan masih diimplementasikan. Tulisan ini menggunakan metode sejarah dengan objek penelitian perkembangan Nurul Islam Seri Bandung (1932). Tujuan penelitian ini secara khusus untuk mengkaji peran K.H. Anwar dalam pengembangan Pondok Pesantren Nurul Islam Seri Bandung 1932-1959. Hasil dari penelitian ini adalah sejarah K.H. Peran Anwar dalam Perkembangan Pondok Pesantren Nurul Islam Seri Bandung 1932-1959.

Keyword : Tokoh Islam, Pesantren, Sejarah Islam, Ogan Ilir, Sumatera Selatan.

\section{Pendahuluan}

Pondok Pesantren memiliki peran penting bagi umat Islam di Indonesia, dalam perjalanan bangsa ini pondok pesantren telah memberi kontribusi besar bagi 
Syarifuddin, Supriyanti, Ajimiliansyah, Tedi Rizki, Muhammad Fikri

pembangunan untuk memcerdaskan umat Islam melalui pendidikan Islam. Melalui Pondok Pesantren inilah banyak tokoh-tokoh pahlawan bangsa yang berasal dari Pesantren, eksistensi pesantren saat ini pun masih dipercaya masyarakat Indonesia sebagai tempat mencari ilmu dalam memperdalam pengetahuan tentang Islam.

Dalam Sejarah Pendidikan di Indonesia Pesantren dapat dikatakan merupakan akar sejarah dan filosofis pendidikan di di Indonesia. Menurut Ziemek dalam Pesantren dalam Perubahan Sosial, bahwasanya Pesantren adalah embrio dan awal berdirinya sejarah pendidikan di Indonesia sampai saat ini. ${ }^{1}$ Pesantren memiliki peranan begitu penting dalam perjalanan pendidikan di Indonesia dan merupakan ciri khas pendidikan Islam di Indonesia.

Begitu pula di daerah kabupaten Ogan Ilir, provinsi Sumatera Selatan terdapat banyak Pesantren-Pesantren dan Ogan Ilir dianggap sebagai kota santri. Kabupaten Ogan Ilir merupakan salah satu kabupaten yang berada di Provinsi Sumatera Selatan. Kabupaten Ogan Ilir dahulunya adalah Kabupaten pemekaran dari Kabupaten Ogan Komering Ilir. Ibukota Kabupaten Ogan Ilir berjarak sekitar 35 km dari Kota Palembang dan berada di jalur lintas timur Sumatera. Peranan Pondok Pesantren begitu besar bagi pendidikan di Ogan Ilir juga Sumatera Selatan. Di Sakatiga disebutkan sebagai awal berkembangnya pesantren di Ogan Ilir, hingga munculnya tiga Pesantren tertua di Sumatera Selatan, yaitu Pondok Pesantren Raudhatul Ulum, Pondok Pesantren Al-Ittifaqiah, dan Pondok Pesantren Nurul Islam di desa Sribandung. ${ }^{2}$

Berdirinya Pondok Pesantren diatas tidak terlepas dari peranan para UlamaUlama besar di Ogan Ilir. Seperti K.H. Anwar bin Kumpul yang merupakan pendiri Pondok Pesantren Nurul Islam yang beliau dirikan pada tahun 1932. Proses K.H. Anwar dalam mendirikan pesantren begitu panjang. K.H. Anwar menuntut ilmu di berbagai tempat dan Ulama-Ulama besar di Ogan Ilir bahkan K.H. anwar di beberapa buku dan penelitian sebelumnya pada tahun 1927 K.H. Anwar melanjutkan pendidikan hingga ke Mekkah, beliau belajar di Madrasah Shaulatiyah. Selanjutnya, melalui perjalanan di berbagai tempat tersebut K.H. Anwar memiliki

1 A. H. Zaini. Pesantren: Akar Pendidikan Islam Nusantara. Jakarta: P3M. 2015.

2 Ilhamudin, J. Suyuthi Pulungan, \& N. Huda. Sejarah Kebudayaan Islam Di Ogan Hilir, 1934-2004. Jurnal Studi Sosial dan Politik.UIN Raden Fatah, Palembang, 107. 2020. 
Syarifuddin, Supriyanti, Ajimiliansyah, Tedi Rizki, Muhammad Fikri

cita-cita mendirikan Pesantren di tanah kelahirannya di desa Seri Bandung, Ogan Ilir, Sumatera Selatan.

Dalam memperdalam ilmu Islam para ulama melakukan ibadah haji dan belajar ilmu agama dalam waktu yang lama. Kemudian kembali ke daerah asal untuk menyebarkan ilmu agama yang didapat kepada masyarakat dan mendirikan kelompok belajar yang belum terlembagakan.

K.H. Anwar bin Kumpul lahir di desa Seri Bandung, Ogan Ilir, Sumatera Selatan dan beliau berasal dari keluarga sederhana bukan berasal dari keturunan keluarga Ulama. Dalam riwayat pendidikan K.H. Anwar di tahun 1919 ia baru menyelesaikan pendidikan di desa Seri Bandung. K.H. melanjutkan pendidikan ke berbagai tempat di Sumatera Selatan, di tahun 1919-1920 ia belajar di Pesantren Meranjat berguru pada K.H. Abdul Hamid. Selanjutnya. K.H. Anwar melanjutkan pendidikan ke Pesantren Sakatiga belajar kepada K. Abdullah Harun, K.H. Ishaq, K.H. Bahri dan K.H. Bakri. Di tahun 1920-1923, K.H. Anwar belajar kepada K.H. Abdul Hamid dan K.H. Ahmad di Pesantren Kayuagung. K.H. Anwar melanjutkan perjalanannya dalam mencari ilmu hingga ke Jambi tahun 1923-1927 di Madrasah Sa'adatud Darain. Hingga di tahun 1927-1930, K.H. Anwar memperdalam ilmu ke Mekkah dan Madinah, disana K.H. Anwar berguru kepada ulama besar di Nusantara untuk belajar ilmu Nahwu dan Shorof dan lainnya. ${ }^{3}$

Pada masa kepemimpinan atau mudir K.H. Anwar Bin H. Kumpul pesantren Nurul Islam Seri Bandung dapat diterima masyarakat sekitar dan juga memiliki keilmuan seperti; nawu sharaf, fiqih, ushul fiqh, mantiq, alfao'id, ilmu Falaq dan lainnya. K.H. Anwar dalam mencetak penerusnya memanajemen kurikulum berbasis standar kompetensi dan mengakomodasi perbedaan-perbedaan individu. ${ }^{4}$

Dalam mengembangkan pesantren Kiai di Pesantren memiliki peran sebagai penggerak dalam memimpin dan mengembangkan Pesantren berdasarkan pola yang ia inginkan, oleh karena itu, Pesantren dapat tetap bereksistensi di zaman sekarang

3 Neli Syafaringga, Syafruddin Yusuf, \& Hudaidah. Peranan Pondok Pesantren Nurul Islam dalam Perkembangan Pendidikan di Kabupaten Ogan Ilir (1932-1980). CRIKSETRA: Jurnal Pendidikan Sejarah ,17. 2018.

4 Zurmarwan. Sejarah Berdiri dan Berkembangnya Pondok Pesantren Nurul Islam Desa Seribandung Kecamatan Tanjung Batu Kabupaten Ogan Ilir Dari Tahun 1932 - 2007. Disertasi UIN Raden Fatah Palembang, 16-17. 2010. 
Syarifuddin, Supriyanti, Ajimiliansyah, Tedi Rizki, Muhammad Fikri

ini berkat sosok Kiai yang memimpinya. Selain disegani karena kepemimpinannya oleh santri, para alumni hingga masyarakat luas, Kiai merupakan pemimpin berpengaruh di Pesantren dalam membuat kebijakan-kebijakan tentang sistem, arah, visi dan misi Pesantren. Kiai seperti itulah yang tegas dalam memimpin dan di taati oleh para bawahannya di Pesantren. Pesantren dan Kiai adalah suatu yang saling berhubungan erat secara dinamis. ${ }^{5}$

Dalam hal ini peneliti tertarik untuk mengkaji peranan K.H. Anwar sebagai pimpinan awal atau mudir di Pesantren Nurul Islam Seri Bandung. Selain itu, perjalanan hidup beliau hingga memiliki gagasan untuk mendirikan Pesantren dan peranan nya di masyarakat karena beberapa penelitian-penelitian sebelumnya masih belum terangkum secara khusus.

Sebelumnya sudah ada penelitian tentang K.H. Anwar dan Pondok Pesantren Nurul Islam di Seri Bandung, Seperti; 1). Tesis yang ditulis oleh Zurmarwan berjudul "Sejarah Berdiri dan Berkembangnya Pondok Pesantren Nurul Islam Desa Seribandung Kecamatan Tanjung Batu Kabupaten Ogan Ilir Dari Tahun 1932 - 2007", membahas mengenai sejarah Pesantren Nurul Islam Seri Bandung. 2). Artikel yang ditulis oleh Nellly Syafaringga tahun 2018 berjudul "Peranan Pondok Pesantren Nurul Islam Dalam Perkembangan Pendidikan di Kabupaten Ogan Ilir (1932-1980)". Artikel ini membahas mengenai peranan Pesantren Nurul Islam Seri Bandung terhadap perkembangan pendidikan di Ogan Ilir dari tahun 1932-1980. 3) artikel yang ditulis oleh Padila tahun 2013 berjudul "Peranan Ulama dalam Perkembangan Islam di Ogan Ilir". Di dalam artikel ini terdapat bahasan tentang K.H. Anwar namun sangat sedikit yang di bahas.

Dari beberapa aritikel dan tesis diatas penelitian tentang peranan K.H. Anwar bagi Pondok Pesantren Nurul Islam Seri Bandung belum banyak diangkat secara khusus. Maka, peneliti mengangkat judul tentang "Peranan K.H. Anwar Dalam Perkembangan Pesantren Nurul Islam Seri Bandung Tahun 1932-1959. Penelitian ini bertujuan membahas mengenai: 1. Riwayat hidup K.H. Anwar (1903-1959) dan

5 S. Fajar. Pesantren di Dunia Melayu antara Tradisionalis dan Modernis (Studi Kasus Kepemimpinan Kiai Pesantren Di Sumatera Selatan). Disertasi UIN Raden Fatah Palembang, 2-3. 2018. 
Syarifuddin, Supriyanti, Ajimiliansyah, Tedi Rizki, Muhammad Fikri

Peranan K.H. Anwar bagi perkembangan Pondok Pesantren Nurul Islam (19321959).

\section{Metode}

Dalam penelitian ini peneliti mengunakan metode penelitian sejarah atau historis dengan pendekatan historis dan sosiologis. Menurut Dedi Irwanto \& Alian Sair metode sejarah adalah langkah-langkah dalam penelitian sejarah. Dalam menuliskan kejadian masa lampau, sejarawan memiliki tahapan-tahapan kerja untuk membuat suatu tulisan sejarah ilmiah berdasarkan sumber-sumber sejarah memiliki prosedur yaitu:

1. Mencari sumber-sumber sejarah;

2. Meneliti sumber-sumber sejarah tersebut dengan kritis;

3. Berdasarkan informasi yang didapatkan dari sumber sejarah berusaha untuk merekontruksi, melalui gambaran masa lampau secara ilmiah;

4. Menyampaikan hasil-hasil rekonstruksi imijinatif tentang masa lampau sehingga sesuai dengan sumber-sumber sejarah tersebut. ${ }^{6}$

Langkah-langkah penelitian ini mengunakan metode sejarah seperti berikut ini:

1. Heuristik, adalah pengumpulan sumber dan data, sumber-sumber yang digunakan meliputi studi pustaka, observasi.

2. Kritik Sumber, adalah langkah meneliti sumber dan data apakah kredibel dan autentik. Kritek sumber ini terbagi menjadi dua kritik intern dan ekstren.

3. Interpretasi atau penafsiran, adalah langkah peneliti dalam merokonstruksi kembali sumber dan data sejarah.

4. Historiografi, adalah pengkajian sejarah dalam meronstruksi dan menulis ulang peristiwa masa lampau berdasarkan sumber-sumber yang di dapatkan.

\footnotetext{
${ }^{6}$ Dedi Irwanto \& Alian Syair. Metodologi Historiografi Sejarah. Yogyakarta: Eja Publisher. 2014.
} 
Syarifuddin, Supriyanti, Ajimiliansyah, Tedi Rizki, Muhammad Fikri

\section{Hasil dan Pembahasan}

A. Riwayat Hidup K.H. Anwar Pendiri Pondok Pesantren Nurul Islam Seri Bandung (1903-1959)

Pada tanggal 6 Agustus 1903, Anwar telah lahir ke dunia cikal bakal menjadi ulama terkenal. Laki-laki ini nanti kemudian hari dari semua muridnya lazim menyebutnya menggunakan sebutan kehormatan K.H. Anwar bin H. Kumpul alias Syekh Anwar. Dari tinggal waktu dia kecil demikian itu, Allah Swt telah memanggil sang ibu kepada pangkuanNya atau meninggal dunia. ${ }^{7}$ K.H. Anwar menjadi mudir atau pimpinan Pesantren sampai dengan beliau meninggal pada tahun 1959.

K.H. Anwar adalah putra daerah Seri Bandung yang dalam proses perjalanan hidup beliau dalam menuntut ilmu cukuplah panjang. Seperti pada tahun 1923-1927 beliau berguru ke Jambi dan belajar hingga ke Mekkah dan Madinah selama 4 tahun dari 1927-1930. setelah belajar di berbagai tempat K.H. Anwar kembali ke desa Seri Bandung untuk berdakwah dan mengajar ke masyarakat setempat, seperti kegiatan Cawisan yang kemudian berkembang menjadi Pondok Pesantren Nurul Islam. ${ }^{8}$

Teringat kembali H. Anwar sewajarnya perawakan yang haus akan ilmu agama Islam. Tujuan menawar keinginannya kepada ilmu agama Islam, dia mengembara menuju berbanding tempat bahwa ditemukan para ulama penting dari daerahdaerah di antaranya:

1. Kyai Abdul Hamid Meranjat, lahir sekitar tahun 1800-an.

2. Kyai Bahri bin Bunga Sakatiga, lahir sekitar tahun 1800-an. Beliau salah satu ulama penting yang bertempat asal di Desa Sakatiga, Kabupaten Ogan Ilir.

3. Kyai H. Harun Sakatiga (lahir sekitar tahun 1800-an) yang mempunyai gelar Sayyidina Harun. Ulama satu ini adalah tenaga pendidik yang menolong Kyai Bahri.

4. Kyai H. Ishaq Sakatiga. Dia merupakan seorang ulama yang bermotivasi pendidikan agama Islam dari Kairo, Mesir. Beliau mempunyai sebutan

\footnotetext{
${ }^{7}$ M. Daud. Biografi Syekh H. Anwar Seribandung: Cahaya Islam dari Uluan Palembang. Jakarta: Mata Aksara. 2017.

8 Neli Syafaringga, Syafruddin Yusuf, \& Hudaidah. Peranan Pondok Pesantren Nurul Islam dalam Perkembangan Pendidikan di Kabupaten Ogan Ilir (1932-1980). CRIKSETRA: Jurnal Pendidikan Sejarah , 17. 2018.
} 
Syarifuddin, Supriyanti, Ajimiliansyah, Tedi Rizki, Muhammad Fikri

kehormatan al-'Amilul Istiqomah (pekerja yang liat) yang bermula dari Tanjung Pinang, Kabupaten Ogan Ilir.

5. H. Anwar berlajar kepada Kyai H. Bakri Sakatiga.

6. H. Anwar berguru kepada Kyai H. Abdul Hamid Kayuagung.

7. Belajar kepada Kyai H. Ahmad Kayuagung.

Sesudah demikian itu, H. Anwar berangkat menuju wilayah Jambi, disebabkan saat itu bapaknya, H. Kumpul memperoleh pekerjaan akan membuat rumah dari daerah Jambi, dia kendati turut dengan bapaknya serta menolak terbaung-buang saja waktu berlatih agama beserta semua ulama penting dari sana. Beliau berguru di Madrasah Sa'adah ad-Darayn. H. Anwar sebagai pendiri Pondok Nurul Islam Seribandung kembali memperdalam kembali ilmu agamanya ke Haramayn (Mekah dan Madinah), paling utama bidang ilmu nahwu serta sharaf. ${ }^{9}$ Pada tahun 1927-1930, K.H. Anwar melanjutkan pendidikan hingga ke Mekkah, beliau belajar di Madrasah Shaulatiyah, K.H. Anwar memperdalam ilmu Tasawuf dan Tarekat Naqsyabandiyah. Di Mekkah K.H. Anwar belajar kepada ulama-ulama besar Nusantara. ${ }^{10}$

Dengan perjalanan berguru di banyak tempat membuat citra K.H. Anwar di masyarakat setempat menjadi kuat. Setelah kembali ke Desa Seri Bandung K.H. Anwar mengajak masyarakat untuk belajar bersama untuk memperdalam ilmu, karena banyak masyarakat setempat yang berkeinginan kuat dan sudah banyak yang bisa membaca dan menghafal Al-Qur'an kerja keras K.H. Anwar pun berhasil. Sehingga masyarakat pun berbondong-bondong untuk mengajak anak mereka untuk belajar dengan beliau hingga jumlah yang begitu banyak K.H. Anwar memutuskan untuk mendirikan Madrasah.

Selain itu, K.H. Anwar juga adalah Ulama yang berperan penting dalam membangun kerukunan sosial dan peradaban di Sumatera Selatan pada abad XX beliau melakukan dakwah mengunakan media mimbar, politik, pendidikan

9 M. Daud. Biografi Syekh H. Anwar Seribandung: Cahaya Islam dari Uluan Palembang. Jakarta: Mata Aksara. 2017.

${ }^{10}$ N. Hasnah Nasution. Ulama dan Politik: Keterlibatan Ulama Sumatera Selatan dalam Politik Praktis dan Community Empowerment Pada Abad XX. UIN Raden Fatah Palembang: Jurnal Studi Sosial dan Politik, 131, 137. 2017. 
Syarifuddin, Supriyanti, Ajimiliansyah, Tedi Rizki, Muhammad Fikri

pesantren, organisasi kemasyarakatan. K.H. Anwar juga aktif dalam bidang politik, terlihat dari rekam jejaknya pada 1945-1947 beliau menjadi ketua Masyumi di wilayah Tanjung Batu, Ogan Komering Ilir, Kordinator Partai PERTI Kabupaten Ogan Komering Ilir pada tahun 1953 dan Sumatera Selatan pada tahun 1954, menjadi Dewan Penasehat PERTI tahun 1955. K.H. Anwar menjadi anggota Konstituen Republik Indonesia (1955) beliau aktif memimpin santri mengambil peran dalam revolusi fisik selama perang kemerdekaan. Dalam hal sosial keagamaan, K.H. Anwar pernah menjadi anggota Majelis Uama Marga Kecamatan Tanjung Batu (1956), bagian dari Majelis Ulama Indonesia. ${ }^{11}$

Dari perjalanan hidup K.H. Anwar beliau adalah sosok yang ulet dalam mencari ilmu hingga berkelana ke berbagai tempat untuk memperdalam ilmu dan jaringan dari ulama-ulama besar bukan hanya ulama dari Ogan Ilir tetapi hingga ke Mekkah dan Madinah. Transformasi ilmu K.H. Anwar kemudian yang akan menjadi ide untuk membangun Pesantren Nurul Islam Seri Bandung, Ogan Ilir, Sumatera Selatan. Peranan K.H. Anwar di bidang sosial masyarakat pun juga begitu besar. Beliau mengambil peran penting pada masa Kolonial dengan aktif mengikuti organisasi-organisasi bahkan mengajak para santri untuk ikut dalam perang revolusi fisik di Ogan Ilir.

\section{B. Peranan KH Anwar Dalam Pembangunan Pondok Pesantren Nurul Islam Seri Bandung (1932-1959)}

Pondok Pesantren Nurul Islam terletak di Desa Seri Bandung Kecamatan Tanjung Batu Ogan Ilir. Desa Seri Bandung berjarak 20 km dari Indralaya, Ibukota Kabupaten Ogan Ilir dan berjarak lebih kurang 61 dari Kota Palembang. Pesantren Nurul Islam didirikan K.H. Anwar bin Haji Kumpul putera asli dari Desa Seri Bandung. Pondok Pesantren Nurul Islam dikenal juga dengan sebutan Pesantren Seri Bandung oleh masyarakat Sumatera Selatan. ${ }^{12}$

${ }^{11}$ N. Hasnah Nasution. The Role of Islamic Preachers in Devoloping Social Harmony and Civilization in South Sumatera in The 20TH Century. Proceeding of International Conference on Da'wa and Communication, Vol. 1 (No. 1), 40. 2019.

${ }^{12}$ (https:// spkt.kemdikbud.go.id/madrasah-saadatud-daraian-ponpes-nurul-islam-seribandung). 
Syarifuddin, Supriyanti, Ajimiliansyah, Tedi Rizki, Muhammad Fikri

Pada tahun 1929 M di Sumatera Selatan munculnya embrio pesantren yang awalnya diberi nama Madrasah Sa'adatud Daren. Kemudian Madrasah ini berubah menjadi Pesantren Nurul Islam Seri Bandung. Pesantren Nurul Islam didirikan oleh K.H. Anwar dan dibantu oleh K.H. Mulkan ibn Thohir (Wakil Mudir, 1932 M-1959 M). Tahun 1925 M, adanya peraturan ketat dari pihak Belanda tentang pelaksanaan pendidikan Islam dan tidak semua Kyai dibolehkan memberikan pelajaran agama. Adanya tekanan dari pihak Belanda ini menyulitkan K.H. Anwar untuk mendirikan pesantren dan pada saat itu para Kyai dicurigai melakukan reformasi baru di bidang pendidikan dan politik. Namun, pada tanggal 1 November 1932 M secara resmi pesantren Nurul Islam Seri Bandung berdiri dengan bantuan tokoh adat setempat yaitu, Pangeran M. Zahier Lubuk Keliat dan Pangeran Tambang Rambang, Ogan Ilir. Dimana dikeluarkanya surat izin dari kepala pemerintah keresidenan (Staatblad No. 494 tahun $1932 \mathrm{M}$ ) dan diubah menjadi (Staatblad No. 372 tahun 1933 M). ${ }^{13}$

Selain itu K.H. Anwar meminta izin pendirian Madrasah kepada persirah Tanjung Batu tetapi izin tersebut akan diberikan jika Madrasah didirikan di Tanjung Batu. Namun, K.H. Anwar menolak dan kemudian meminta bantuan Pangeran Lubuk Keliat. Pangeran Lubuk Keliat pun memberikan izin dan Madrasah akhirnya berdiri dengan nama Sa'addatud Daren dan berubah menjadi Sekolah Nurul Islam dengan memiliki tiga lokal. ${ }^{14}$

Dalam wawancara dengan Ustadz Ali Usman (Seketaris Pesantren Nurul Islam) menerangkan bahwa diawal berdirinya Madrasah diberi nama menjadi sekolah Nurul Islam (SNI). Diawal berdiri Pondok Pesantren guru-guru nya hanya sebatas tamatan Ibtidaiyah (SD), sementara untuk guru-guru tersebut harus bisa membaca dan menulis Arab, dan menguasai salah satu kitab seperti Fiqih, Sejarah Nabi Muhammad, Mafhum Shorof dan lainnya. K.H. Anwar harus berpindahpindah tempat untuk mengajar di sekitar Desa Seri Bandung seperti mengajar di rumah-rumah warga setempat. Akhirnya, berkat bantuan masyarakat dapat

13 Hafidhuddin H. STUDI ISLAM MELAYU: Melacak Karya-karya Kyai H. Anwar SeribandungPalembang. Tamaddun: Jurnal Kebudayaan dan Sastra Islam, 16(2), 257-296. 2016.

${ }^{14}$ M. Daud. Biografi K.H. Anwar bin Kumpul H. Kumpul Cahaya Islam dari Uluan Palembang. Palembang: Noerfikri. 2017. 
Syarifuddin, Supriyanti, Ajimiliansyah, Tedi Rizki, Muhammad Fikri

didirikannya bangunan lokal untuk kelas Ibtidaiyah dan bersebelahan dengan Sekolah Rakyat (SR) yang kemudian pindah ke daerah darat Desa Seri Bandung.

Madrasah Nurul Islam Seri Bandung yang didirikan K.H. Anwar adalah Madrasah pertama di Sumatera Selatan yang menganut sistem Pondok dan diawal berdirinya sudah ada sekitar 35 murid. K.H. Anwar selain aktif mengajar di Pesantren nya juga aktif berdakwah di berbagai tempat di Ogan Ilir. Pada tahun 1949 dibuatnya tempat belajar untuk santriwati setelah sebelumnya sudah ada tempat belajar putra. ${ }^{15}$

Berdasarkan wawancara dengan Bapak Darwis Dumyati (cucu dari K.H. Anwar) K.H. Anwar pada awalnya belum memiliki rencana untuk medirikan Pesantren. Karena beliau sudah memiliki keilmuan yang tinggi, beliau merasa ada suatu keharusan untuk menyampaikan ilmunya ke tengah-tengah masyarakat. Pada awalnya K.H. Anwar mengadakan pengajian dari rumah ke rumah di beberapa dusun di wilayah Kecamatan Tanjung Batu. Dengan antusias masyarakat Seri Bandung yang tinggi untuk belajar ilmu agama peranan masyarakat setempat pun begitu besar dalam membantu K.H. Anwar seperti membantu mendirikan asrama,bahkan ada masyarakat yang menginfakan tanah kepada K.H. Anwar untuk mendirikan Pesantren.

Pada masa kepemimpinan atau mudir K.H. Anwar Bin H. Kumpul pesantren Nurul Islam Seri Bandung dapat diterima masyarakat sekitar dan juga memiliki keilmuan seperti; nawu sharaf, fiqih, ushul fiqh, mantiq, alfao'id, ilmu falaq dan lainnya. K.H. Anwar dalam mencetak penerusnya memanajemen kurikulum berbasis standar kompetensi dan mengakomodasi perbedaan-perbedaan individu. ${ }^{16}$

Dalam hal-hal pengelolaan kurikulum K.H. Anwar setelah mendirikan Pesantren Nurul Islam Seri Bandung pada tahun 1938 telah menetapkan pokok-pokok kurikulum Pesantren, yaitu dalam bidang fiqih mengikuti paham Syafi'iyyah, dalam bidang tauhid mengikuti paham Asy'ariyyah, sementara dalam bidang tasawwuf

\footnotetext{
${ }^{15}$ Ilhamudin. Jejak Penyebaran Islam di Tanah Ogan Ilir. Jurnal I'TIBAR, 113-117. 2019

16 Zurmarwan. Sejarah Berdiri dan Berkembangnya Pondok Pesantren Nurul Islam Desa Seribandung Kecamatan Tanjung Batu Kabupaten Ogan Ilir dari Tahun 1932 - 2007. Disertasi UIN Raden Fatah Palembang, 16-17. 2010.
} 
Syarifuddin, Supriyanti, Ajimiliansyah, Tedi Rizki, Muhammad Fikri

mengikuti paham Junaid Al-Bagdadi. Ketiga paham ini lah yang menjadi ruh dalam perjuangan Pesantren Nurul Islam Seri Bandung. ${ }^{17}$

Pesantren Nurul Islam Seri Bandung dalam hal kurikulum dan sistem pembelajaran mengikuti Pondok Pesantren Darussalm Labuhan Haji Aceh Selatan padaa awal berdirinya tahun 1932 karena pendiri Pondok Pesantren Nurul Islam merupakan alumni dari pesantren di Aceh Selatan tersebut. Visi dan Misi disesuaikan dengan visi dan misi K.H. Anwar sebagai pendiri dan tetap mempertahankan ajaran Ahl Al-Sunnah Wa Al-Jama'ah. Sementara sistem pendidikan yaitu sistem salafiyah atau tradisional. ${ }^{18}$

K.H. Anwar banyak menuliskan kitab-kitab dan dijadikan kitab belajar santri. Adapun karya-karya nya seperti: 'Aqāid al- Īmān, Aqîdat al-Ghulâm, Sejarah Nabi Muhammad SAW, at-Taqrir, Mafhûm al-Jurmiyyah, Majmu'ah fi al-Asalah alNahwiyyah, I'rab al-Kalimat, Mafhûm Tajwid, Mafhûm al-Sharaf, al-farâidh, alFalakiyyat, Muhadatsat, al-Naghâm. Dan karya-karya K.H. Anwar yang tidak sempat didokumentasikan seperti: Tarjamah Taqrib alMaqshud, Tahlil, Amalan Shalat. Dari karya-karya K.H. Anwar lebih banyak terfokus kepada ilmu alat dan fiqih. K.H. Anwar sebagai pendiri Pondok Pesantren Nurul Islam lebih memfokuskan bidang ilmu alat sehingga menjadi suatu ciri khas Pesantren Nurul Islam. ${ }^{19}$

Pada awal berdirinya Pesantren Nurul Islam Seri Bandung, yaitu pada masa kepemimpian K.H. Anwar (Kiyai generasi pertama) ajaran tasawwuf cukup berkembang. K.H. Anwar mengamalkan tarekat Naqsabandiyah tetapi hingga saat ini ajaran tassawuf di Pesantren Nurul Islam Seri Bandung tidak lagi diamalkan tarekat oleh para ustadz di Pesantren. K.H. Anwar juga membuat peraturan tata tertib seperti kewajiban kepala gundul dan memakai kain sarung bagi semua santri putra. Peraturan tersebut bertujuan untuk memberi batasan bagi santri yang keluar komplek pondok dan juga sebagai identitas khusus bagi para santri Pesantren Nurul

\footnotetext{
${ }^{17}$ Muhajirin. Pemetaan Hadits di Pesantren Sumatera Selatan Riwayah: Jurnal Studi Hadis.., 28. 2018.

${ }_{18}$ Fajar, S. Pesantren di Dunia Melayu antara Tradisionalis dan Modernis (Studi Kasus Kepemimpinan Kiai Pesantren Di Sumatera Selatan). Disertasi UIN Raden Fatah Palembang, 2-3. 2018.

${ }^{19}$ N. Hasnah Nasution. Ulama dan Politik: Keterlibatan Ulama Sumatera Selatan dalam Politik Praktis dan Community Empowerment Pada Abad XX. UIN Raden Fatah Palembang: Jurnal Studi Sosial dan Politik, 131, 137. 2017.
} 
Syarifuddin, Supriyanti, Ajimiliansyah, Tedi Rizki, Muhammad Fikri

Islam Seri Bandung. Tetapi, dimasa sekarang peraturan tersebut tidak diwajibkan oleh para Ustadz di Pesantren. Salah satu wasiat dari K.H. Anwar adalah tradisi membaca Al-Qur'an yang tetap ada hingga sekarang. Hukuman yang dibuat K.H. Anwar terhadap santri pada saat mengaji dengan memberikan teguran lisan dan rajam yaitu hukuman bersifat fisik. Tradisi barzanji atau marhabah merupakan kegiatan unggulan pada masa kepemimpinan K.H. Anwar. Kegiatan tersebut terkait dengan dakwah beliau ke berbagai daerah. K.H. Anwar sangat sering mengisi acara cawisan (kegiatan ceramah atas undangan warga, mushala dan masjid). ${ }^{20}$

Pada tahun 1949, Pesantren Nurul Islam berkembang banyak dan mendirikan jenjang pendidikan tsanawiyah (SMP) dan madrasah ibtidaiyah khusus santriwati dibuka dengan pimpinan putri K.H. Anwar, Halimah. K.H. Anwar di tahun 1949 inilah memasukan ilmu pengetahuan umum dalam kurikulum pesantren. Selain itu, dimulainya kegiatan muhadharah (latihan ceramah), qasidah, tahlil dan kegiatan lainnya sebagai pendidikan ekstrakurikuler. Dalam hal pembelajaran Pesantren Nurul Islam mengunakan metode sorogan, bandrongan, dan klassikal. K.H. Anwar menjadi mudir atau pimpinan Pesantren sampai dengan beliau meninggal pada tahun 1959. Setelah beliau mendirikan Pesantren Nurul Islam sudah menghasilkan penerusnya yang menjadi ulama dan guru agama yang tersebar di Sumatera Selatan dan lainnya. ${ }^{21}$

Dari penjelasan diatas K.H. Anwar sebagai pendiri Pesantren Nurul Islam Seri Bandung memiliki peranan yang besar. Seperti membuat kurikulum dan sistem pembelajaran di awal berdirinya Pesantren Nurul Islam. Kurikulum yang dibuat K.H. Anwar berdasarkan keahlian yang beliau miliki yang mencakup tiga pokok ilmu yaitu fiqih, tauhid dan tasawwuf. Tradisi Pesantren seperti membaca Al-Quran dan tata tertib santri masih diterapkan yang membuktikan bahwa system salafiyah atau tradisional masih diterapkan. Pengaruhnya di masyarakat setempat pun begitu kuat dan memiliki hubungan yang baik. Masyarakat Desa Seri Bandung begitu

${ }^{20}$ Munir. The Continuity and the Culture Change of Pesantren in South Sumatra. Ta'dib: Journal of Islamic Education, 21, 89-93. 2016.

${ }^{21}$ N. Hasnah Nasution. Ulama dan Politik: Keterlibatan Ulama Sumatera Selatan dalam Politik Praktis dan Community Empowerment Pada Abad XX. UIN Raden Fatah Palembang: Jurnal Studi Sosial dan Politik, 131, 137. 2017. 
Syarifuddin, Supriyanti, Ajimiliansyah, Tedi Rizki, Muhammad Fikri

antusia untuk belajar agama dengan K.H. Anwar hingga beridirinya Pesantren Nurul Islam yang sudah begitu terkenal di Sumatera Selatan.

Berdasarkan dari segi keilmuan K.H. Anwar secara garis besar kurikulum pada masa beliau merupakan kurikulum pendidikan Islam dengan didominasi oleh pelajaran keagamaan seperti fiqih, ilmu alat, ceramah, tauhid, tasawwuf yang sekarang sudah tidak ada lagi di Pesantren Nurul Islam. Ilmu-ilmu agama seperti diatas hingga kini masih dipelajari tanpa ada pengembangan selain ilmu agama. Jika dibandingkan dengan Pesantren yang sudah maju di Sumatera Selatan ilmu umum dan ilmu teknologi sudah diformulasikan dengan kurikulum lama sehingga menjadi ciri khas baru bagi pendidikan Islam.

Begitu pula dengan pesantren Nurul Islam Seri Bandung dengan perkembangan zaman kurikulum haruslah mengikuti perkembangan zaman dan isi kurikulum pun semakin meluas. Dalam penyusunan kurikulum pendidikan Islam harus memiliki prinsip-prinsip seperti memilik ruh Islamiyah, Universal, Balancing, sesuai dengan perkembangan psikologis, memperhatikan lingkungan sosial. ${ }^{22}$ Pesantren Nurul Islam Seri Bandung haruslah menyesuaikan kurikulum dengan perkembangan zaman sekarang dan tidak terbatas hanya pada sistem peninggalan K.H. Anwar agar eksistensi Pesantren tetap terjaga dan diakui di tengah-tengah masyarakat.

\section{Kesimpulan}

Dari penelitian ini peneliti dapat menyimpulkan bahwa peranan K.H. Anwar dalam pembangunan Pondok Pesantren Nurul Islam Seri Bandung sangatlah besar. Dimulai dari cita-citanya mendirikan Pesantren yang ia awali dengan berdakwah di desa asalnya dan berbagai daerah hingga akhirnya cita-cita berdirinya Pesantren itu terwujud pada 1 November 1932. Walaupun harus mendapat kesulitan oleh Pemerintah Kolonial Belanda. Namun, pada tanggal 1 November 1932 M secara resmi pesantren Nurul Islam Seri Bandung berdiri dengan bantuan tokoh adat setempat yaitu, Pangeran M. Zahier Lubuk Keliat dan Pangeran Tambang Rambang, Ogan Ilir. Dimana dikeluarkanya surat izin dari kepala pemerintah keresidenan

${ }^{22}$ A. Nata. Sejarah Pendidikan Islam: Pada Periode Klasik dan Pertengahan. Jakrarta: RajaGrafindo Persada. 2004. 
Syarifuddin, Supriyanti, Ajimiliansyah, Tedi Rizki, Muhammad Fikri

(Staatblad No. 494 tahun 1932 M) dan diubah menjadi (Staatblad No. 372 tahun 1933 M).

Perjalanan K.H. Anwar dalam mencari ilmu ke berbagai tempat dan berguru kepada Ulama-Ulama besar dapat berguna baginya disaat ia telah berhasil mendirikan Pesantren Nurul Islam Seri Bandung. Pesantren Nurul Islam yang beliau dirikan telah bejasa bagi perkembangan dunia pendidikan di Ogan Ilir.

K.H. Anwar menjadi mudir atau pimpinan Pesantren sampai dengan beliau meninggal pada tahun 1959. Setelah beliau mendirikan Pesantren Nurul Islam sudah menghasilkan penerusnya yang menjadi ulama dan guru agama yang tersebar di Sumatera Selatan dan lainnya. K.H. Anwar banyak menuliskan kitab-kitab dan dijadikan kitab belajar santri. Dari karya-karya K.H. Anwar lebih banyak terfokus kepada ilmu alat dan fiqih. K.H. Anwar sebagai pendiri Pondok Pesantren Nurul Islam lebih memfokuskan bidang ilmu alat sehingga menjadi suatu ciri khas Pesantren Nurul Islam.

Berdasarkan dari segi keilmuan K.H. Anwar secara garis besar kurikulum pada masa beliau merupakan kurikulum pendidikan Islam dengan didominasi oleh pelajaran keagamaan seperti fiqih, ilmu alat, ceramah, tauhid, tasawwuf yang

sekarang sudah tidak ada lagi di Pesantren Nurul Islam. Ilmu-ilmu agama seperti diatas hingga kini masih dipelajari tanpa ada pengembangan selain ilmu agama. Jika dibandingkan dengan Pesantren yang sudah maju di Sumatera Selatan ilmu umum dan ilmu teknologi sudah diformulasikan dengan kurikulum lama sehingga menjadi ciri khas baru bagi pendidikan Islam. pesantren Nurul Islam Seri Bandung dengan perkembangan zaman kurikulum haruslah mengikuti perkembangan zaman dan isi kurikulum pun semakin meluas. Dalam penyusunan kurikulum pendidikan Islam harus memiliki prinsip-prinsip seperti memilik ruh Islamiyah, Universal, Balancing, sesuai dengan perkembangan psikologis, memperhatikan lingkungan. Pesantren Nurul Islam Seri Bandung haruslah menyesuaikan kurikulum dengan perkembangan zaman sekarang dan tidak terbatas hanya pada sistem peninggalan K.H. Anwar agar eksistensi Pesantren tetap terjaga dan diakui di tengah-tengah masyarakat. 
Syarifuddin, Supriyanti, Ajimiliansyah, Tedi Rizki, Muhammad Fikri

K.H. Anwar telah menciptakan Pesantren dengan kerja keras nya seperti menuliskan kitab-kitab, merumuskan kurikulum, peraturan tata tertib, tradisi yang saat ini masih diterapkan sebagian dan juga memperbaiki pendidikan Islam di daerah asalnya hingga pesantren ini dikenal di Sumatera Selatan. Peranan K.H. Anwar bagi dunia pendidikan Islam di Sumatera Selatan begitulah besar karena sudah mencetak para alumnus yang sukses di tengah-tengah masyarakat.

\section{Daftar Pustaka}

Daud, M. (2017). Biografi Syekh H. Anwar Seribandung: Cahaya Islam dari Uluan Palembang. Jakarta: Mata Aksara.

Daud, M. (2017). Biografi K.H. Anwar bin Kumpul H. Kumpul Cahaya Islam dari Uluan Palembang. Palembang: Noerfikri.

Dedi, I., \& Syair, A. (2014). Metodologi Historiografi Sejarah. Yogyakarta: Eja Publisher. Fajar, S. (2018). Pesantren di Dunia Melayu antara Tradisionalis dan Modernis (Studi Kasus Kepemimpinan Kiai Pesantren Di Sumatera Selatan). UIN Raden Fatah Palembang, 2-3. (Unpublished dissertation)

Hafidhuddin, H. (2016). STUDI ISLAM MELAYU: Melacak Karya-karya Kyai H. Anwar Seribandung-Palembang. Tamaddun: Jurnal Kebudayaan dan Sastra Islam, 16(2), 257-296.

Hasnah Nasution, N. (2019, September 24-26). The Role Of Islamic Preachers in Devoloping Social Harmony and Civilization in South Sumatera in The 20TH Century.. Proceeding of International Conference on Da'wa and Communication, Vol. 1(No. 1), 40. (Conference paper/Proceeding)

Hasnah Nasution, N. (2017). Ulama dan Politik: Keterlibatan Ulama Sumatera Selatan dalam Politik Praktis dan Community Empowerment Pada Abad XX. UIN Raden Fatah Palembang: Jurnal Studi Sosial dan Politik, 131, 137.

https:/ / spkt.kemdikbud.go.id/madrasah-saadatud-daraian-ponpes-nurul-islamseribandung. (n.d.). Retrieved 12, 11, 2020

Ilhamudin. (2019). Jejak Penyebaran Islam di Tanah Ogan Ilir. Jurnal I'TIBAR , 113117.

Ilhamudin, Suyuthi Pulungan, J., \& Huda, N. (2020). Sejarah Kebudayaan Islam Di Ogan Hilir, 1934-2004. Jurnal Studi Sosial dan Politik.UIN Raden Fatah, Palembang, 107.

Irwanto, D., \& Syair, A. (2014). Metodologi Historiografi Sejarah. Yogyakarta: Eja Publisher.

Muhajirin. (2018). Riwayah: Jurnal Studi Hadis. Pemetaan Hadits di Pesantren Sumatera Selatan., 28.

Munir. (2016, June 1). The Continuity and the Culture Change of Pesantren in South Sumatra. Ta'dib: Journal of Islamic Education, 21, 89-93. 
Syarifuddin, Supriyanti, Ajimiliansyah, Tedi Rizki, Muhammad Fikri

Padila. (2013). Peranan Ulama dalam Perkembangan Islam di Ogan Ilir. Tamaddun: Jurnal Kebudayaan dan Sastra Islam.

Nata, A. (2004). Sejarah Pendidikan Islam: Pada Periode Klasik dan Pertengahan. Jakrarta: RajaGrafindo Persada.

Syafaringga, N., Yusuf, S., \& Hudaidah. (2018). Peranan Pondok Pesantren Nurul Islam Dalam Perkembangan Pendidikan di Kabupaten Ogan Ilir (1932-1980). CRIKSETRA: Jurnal Pendidikan Sejarah , 17.

Zaini, A. H. (2015). Pesantren: Akar Pendidikan Islam Nusantara. Jakarta: P3M.

Zurmarwan. (2010). Sejarah Berdiri dan Berkembangnya Pondok Pesantren Nurul Islam Desa Seribandung Kecamatan Tanjung Batu Kabupaten Ogan Ilir Dari Tahun 1932 - 2007. UIN Raden Fatah Palembang, 16-17. 